\title{
Population Projection under Changing Fertility Conditions
}

\author{
Tika Ram Aryal \\ Central Department of Statistics \\ Tribhuvan University, Kathmandu \\ E-mail: traryall@gmail.com
}

\begin{abstract}
This paper attempts to derive model for population projection under gradual change in fertility schedule on stability conditions using birth trajectory at time $\mathrm{t}$ for $0<t \leq a$. The projected population can be obtained when the data of the rate of natural increase, net reproduction rate, age variance of the net maternity function, birth rate of the initial stable population along with its age distribution are available of the population.
\end{abstract}

Keywords: Population projection, stable population, birth trajectory, maternity function, net reproduction rate.

\section{INTRODUCTION}

Models for the projection of population under stability conditions on birth trajectory at any time are well known to all the demographers and social scientists due to wide applications in designing policy and planning purposes. It considers female population, which is closed to migration under unchanging pattern of fertility as well as mortality schedule over a long period of time, which results with a stable condition of population to a fixed age structure and its size increases with a constant growth rate (Islam, 2001). If the growth rate is approaches to zero, the population size would be constantly fixed and population is said to be stationery state or replacement level. There are several techniques to execute population projection and some of them are logistic, Gompertz, deterministic, etc, which provided population projection of any population (Aryal, 2011, Regmi, 2014). The population projection through components methods and stable or quasi-stable population methods are some of the widely used popular methods. However, projection of population by the method of stable population techniques has become of more popular due to its simplicity and mathematical treatment. The population growth models have been developed with changing vital rates under stable and stationery conditions.

The application of stable population models for the projection and prediction of future size of population beyond the traditional assumptions of constant of vital rates have been emphasised, and which have been hottest topics of for research interest among demographers, policy-makers and researchers (Aryal, 2008; Coale, 1972; Mitra, 1985, 1990). A number of researchers have made different efforts to project the population size for the varying path of the fertility schedules under stability state by utilising the data from different countries (Aryal; 2013, Islam, 2001; Keyfitz, 1971, 1977; Lotka, 1907; Mitra, 1990).

The birth trajectory concept has been introduced and widely used for the prediction of future population in the stability condition. Frauenthal (1975) developed an idea of an abrupt shift in fertility schedule $m(x, t)=\rho m(x)$ and the birth trajectory $B(t)=\rho b e^{r t}$ at time $\mathrm{t}$ for $0<t \leq a$, where ' $a$ ' is the lower limit of the reproductive period and $\rho$ is the positive constant provided that $0<\rho<1$. In line of this, Mitra (1976) developed a concept of an age dependent abrupt change in fertility schedule as $m(x, t)=e^{-r x} m(x)$ and the birth trajectory is

$$
B(t)=b e^{-r t} \int_{0}^{\infty} e^{-2 r x} p(x) m(x) d x \text { for } t \leq a .
$$

In this context, this paper attempts to derive model for population projection under gradual change in fertility schedule on stability condition using birth trajectory at time $\mathrm{t}$ for $0<t \leq a$.

\section{MATERIALS AND METHODS}

\section{Model}

Lotka (1939) developed a renewal equation for female birth, $\mathrm{B}(\mathrm{t})$, at time $\mathrm{t}$ of a population which is closed to migration. The equation is given as:

$$
B(t)=\int_{t}^{\infty} l(x-t) \frac{p(x)}{p(x-t)} m(x, t) d x+\int_{0}^{t} B(t-x) p(x) m(x, t) d x .
$$

where $1(x)$ denotes the age distribution at time $t=0, p(x)$ refers to the female populations and they survive at age 
$\mathrm{x}, \mathrm{m}(\mathrm{x}) \mathrm{dx}$ is the probability that a female of age $\mathrm{x}$ will bear a female child in the next $\mathrm{dx}$ period of her life.

For the stable population, $l(x)=b e^{-r x} p(x)$ and implies that

$\frac{l(x-t)}{p(x-t)}=b e^{-r x} e^{x t}$

Where $r$ is the stable population growth rate at time $t=0$ and $\mathrm{b}$ denotes the instantaneous birth rate $\mathrm{at} \mathrm{t}=0$.

Now from equation (1) and (2) for $t>0$, we have

$$
B(t)=b e^{r t} \int_{t}^{\infty} e^{-r x} p(x) m(x, t) d x+\int_{0}^{t} B(t-x) p(x) m(x, t) d x
$$

For $t \leq a$, in equation (3), which indicating that the components of $\int_{0}^{t} B(t-x) p(x) m(x, t) d x$ equal to zero. Thus the equation (3) reduces to

$$
B(t)=b e^{r t} \int_{t}^{\infty} e^{-r x} p(x) m(x, t) d x
$$

If $\mathrm{m}(\mathrm{x}, \mathrm{t})$ changes abruptly, indicating that $\mathrm{m}(\mathrm{x}, \mathrm{t})$ becomes

$$
m(x, t)=e^{-r x} m(x)
$$

Using equations (4) and (5), we get

$$
B(t)=b e^{r t} \int_{0}^{\infty} e^{-2 r x} p(x) m(x) d x \text {, for } t \leq a
$$

The assumption made by Mitra (1976) that the maternity function is approximately normal, which implied the integral part of equation (6) comes out to be

$$
\int_{\alpha}^{\beta} e^{-2 r x} p(x) m(x) d x=\frac{e^{r^{2} \sigma^{2}}}{R_{0}}
$$

Where $\mathrm{R}_{0}$ is the net maternity reproduction rate and $\sigma^{2}$ is the variance of the net maternity function $\mathrm{p}(\mathrm{x}) \mathrm{m}(\mathrm{x})$.

Thus the birth trajectory of equation (6) can be rewritten by using equation (7) as,

$$
B(t)=b \frac{e^{r t+r^{2} \sigma^{2}}}{R_{0}} \quad \text { for } t \leq a
$$

It is obvious fact that the birth trajectory from equation (8) provides smaller values as compared to that of the usual birth trajectory $\left(b e^{r t}\right)$ obtained from the stable population theory. Finally, we have $\frac{e^{r^{2} \sigma^{2}}}{R_{0}}<1$ for any $r>0$

Hence the population size of the birth trajectory as adopted the concept of Yadava (1985) comes out to be,

$\left[1-\left\{1-\frac{e^{r^{2} \sigma^{2}}}{R_{0}}-\right\}_{0}^{t} b e^{-r a} p(a) d a\right] e^{r t}$

The integral part of $\int_{0}^{t} b e^{-r a} p(a) d a$ appeared in the equation (10) refers to the proportion of population upto age $\mathrm{t}$.

\section{RESULTS}

\section{Application with special cases}

Now we state some of the following special results regarding the population size based on the birth trajectory of equation (10) as given below.

(i) If the value of $e^{r^{2} \sigma^{2}}=1$ in a population where there were several combinations of $\mathrm{r}$ and $\sigma^{2}$ naturally hold, then the equation (10) reduces to

$$
\left[1-\left\{1-\frac{1}{R_{0}}-\int_{0}^{t} b e^{-r a} p(a) d a\right] e^{r t}\right.
$$

(ii)If the current age specific fertility rate, $m(x, t)=m(x) \frac{R_{0}^{*}}{R_{0}}\left(\right.$ Keyfitz, 1975) where $1<R_{0}^{*}<R_{0}$, a gradual change in fertility schedule, then the population size for $t \leq a$ of equation (10) comes out to be

$$
\left[1-\left\{1-\frac{R_{0}^{*}}{R_{0}}-\int_{0}^{t} b e^{-r a} p(a) d a\right] e^{r t}\right.
$$

(iii) If fertility schedule represents a linear function, then the current age specific fertility rate, $m(x, t)=(1-r x) m(x)$. The birth trajectory of equation (4) reduces to

$$
B(t)=b e^{r t} \int_{t}^{\infty} e^{-r x}(1-r x) m(x) p(x) d x
$$

The equation (13) is also re-written as

$$
B(t)=b e^{r t}(1-r M)
$$

where $M=\int_{t}^{\infty} a e^{-r x} m(x) p(x) d x$, which is the mean age of child bearing in the stable population theory. 
Thus the total population size at time $t$ under such birth trajectory is given as,

$$
\left[1-\{1-r M\} \int_{0}^{t} b e^{-r a} p(a) d a\right] e^{r t} \text { for } t \leq \alpha
$$

The equation (15) gives a slightly higher estimate of the projected population sizes as compared to that of equation (10) due to less reduction in fertility schedule.

In fact, $e^{-r x}=(1-r x)$ for any $r>0$ and if $e^{r^{2} \sigma^{2}}=R_{0}^{*}$, which is a new reproduction rate in the changed fertility schedule. On this concept, the equations (10) and (12) would project the same size of population where equation (12) would consider the value of $R_{0}^{*}$, a desired net reproduction rate under a gradual change in fertility schedule.

The model derived above provides projection of female population $\left(P_{f}(t)\right)$. The male population $\left(P_{m}(t)\right)$ projection can be obtained by using following expression.

$P_{m}(t)=\frac{e_{m}^{0}}{e_{f}^{0}} \times P_{f}(t) \times S R$

Where $P_{m}(t)$ be the projected male population at time t, $P_{f}(t)$ be the projected female population at time t, $e_{m}^{0}$ and $e_{f}^{0}$ refer to the life expectancy for males and females respectively, and SR represents the sex ratio at birth.

\section{CONCLUSION}

The paper considers the population projection with the help of the birth trajectory of different path of fertility schedule under stable condition at any time $t$ for $0<t \leq a$. For obtaining the projected population, we need the values of the rate of natural increase $(r)$, net reproduction rate $\left(R_{0}\right)$, age variance of the net maternity function $\left(\sigma^{2}\right)$, and birth rate (b) of the initial stable population along with its age distribution, $\mathrm{m}$ (a) so that the proportion of persons below a particular age and mean age of person in various age ranges could be computed.

For instance, the value of $\mu$ and $\sigma^{2}$ can be computed as follows.

$\mu=\frac{R_{1}}{R_{0}}$ and $\sigma^{2}=\left(\frac{R_{1}}{R_{0}}\right)-\left(\frac{R_{1}}{R_{0}}\right)^{2}$ where $R_{i}=\int_{a}^{\beta} x^{i} m(x) p(x P d x$.

If the reliable data are available, the projection of population size would easily be projected.

\section{REFERENCES}

Aryal, T.R. 2008. Migration and Occupational Mobility in Nepal. Paluwa Prakashan, Bagbazzar, Nepal.

Aryal, T.R. 2011. Fertility Dynamics of Nepal. Ekta Books, Kathmandu, Nepal.

Aryal, T.R. 2013. Application of demographic models to investigate levels, differentials and determinants of fertility of Nepal. Journal of Institutes of Science and Technology 18 (1):148-156.

Coale, A.J. 1972. The growth and structure of human populations: a mathematical investigation. Princeton, Princeton University Press, New Jarsey.

Frauenthal, J.C. 1975. Birth trajectory under changing fertility conditions. Demography 12:447-454.

Islam, S. 2001. Some demographic models and their applications: particular references to Bangladesh. $\mathrm{PhD}$ thesis, Department of Statistics, BHU.

Keyfitz, N. 1977. Applied Mathematical Demography. New York. John Wiley and Sons.

Keyfitz, N. 1971. On the momentum of population growth. Demography 8: 71-80.

Lotka, A.J. 1907. Mode of growth of material aggregates. American Journal of Science 24:199-216.

Mitra, S. 1976. Influence of instantaneous fertility decline to replacement level on population growth: alternative models. Demography 13:513-519.

Mitra, S. 1985. A model of changing net maternity rates leading to stability. Demography India 14(1):13037.

Mitra, S. 1990. A birth model with oscillating rate of growth. Janasamkhya 8(1):35-40.

Regmi, L.K. 2014. An overview of population growth trends of Nepal. Journal of Institutes of Science and Technology 19 (1): 57-61.

Yadav, S.N. 1993. On some migration and population growth models. $\mathrm{PhD}$ thesis, Department of Statistics, BHU. 